\title{
The Thinking of Campus Football Under the Haze Fog weather
}

$$
\text { Li Yanhong1,a, YanYunQi',b }
$$

${ }^{1}$ The Department of Physical Education of Hubei university of Science and Technology, Xianning ,Hubei ,China

${ }^{2}$ Xianning experimental foreign language school Xianning ,Hubei ,China a38961697@qq.com b58007569@qq.com

\section{Keywords: Haze fog, Campus football, Carrying out , Thinking}

\begin{abstract}
Since the development of campus football, series of activities have been carried out all over the country and have achieved certain results. As the haze fog weather seriously affected campus football, we should take certain measures in face of haze fog weather so that the campus football activities will continue. We tried to find out relatively reasonable and effective ways through communication and discussion, in order to keep the campus football on. This paper puts forward several points of view and opinions on campus football under the haze fog weather, which is aimed at attracting the attention of the fellows in sports education circles.
\end{abstract}

\author{
雾霍天气下开展校园足球工作的思考 \\ 李燕红 ${ }^{1 a}$, 严运旗 ${ }^{2 b}$ \\ 1 湖北科技学院体育学院, 咸宁, 湖北, 中国 \\ 2咸宁实验外国语学校, 咸宁, 湖北, 中国 \\ a38961697@qq.com, b58007569@qq.com
}

关键词:雾䨪, 开展, 校园足球, 思考

中文摘要: 全国校园足球活动开展以来, 校园足球活动在各地校园足球领导小组的领导下开展 了一系列的活动并取得了一定的成效, 但近几年严重的雾䨪天气严重的影响了校园足球的开 展, 面对雾需天气的日益严重, 我们有必要针对这种伤害人体健康的天气环境进行思考和分 析, 及时通过交流和讨论, 研究相对合理、有效的校园足球的开展方式。本文就雾䨪天气情 况下的校园足球的开展提出几点看法和意见，旨在引起体育教育界同仁的重视。

\section{1. 引言}

“雾霳” 从2012 年才进入我们的视野后, 每年秋冬就开始发挥它的威力。近年来, 全国 各地区多次出现雾需天气, 中国气象局不断升级对雾䨪的预警系统, 大气中的PM2. 5 指数 严重超标，空气非常污浊，可谓是 “十面霧伏”。

教育部部长袁贵仁在7月28日召开的全国学校体育工作座谈会上表示: “今年起, 将逐步 建立健全小学、初中、高中和大学四级足球联赛机制, 教育部将重点发展校园足球项目”。 校园足球就在各级中小学开展得如火如茶。但是近几年严重的雾䨝天气严重的影响了校园足 球的开展, 那么当校园足球的开展遇上雾霧天气时, 校园足球应该采取怎样的应对措施? 采 
取什么形式来开展校园足球? 在雾䨪天气时校园足球主要开展哪些内容, 运动量多少等都成 为学校一线体育老师需要进一步思考的问题。

\section{2. 雾䨪天气常态化下校园足球的应对策略}

\section{1 加强校园足球文化建设}

校园足球文化泛指校园内一切与足球相关的活动，是学校体育文化的重要组成部分，是 全校师生对足球运动运动的思想, 行为以及围绕足球运动而开展的文化活动。雾霧天气常态 化严重影响了校园足球的正常的教学与训练。

2.1.1 提高体育教师的综合素质。

体育教师作为学校体育的组织者和实施者, 是学生学习体育知识的教育者和指导者, 是 传递和宣传校园足球文化的中坚力量, 体育教师自身的足球能力以及文化修养直接影响到学 生对足球的热爱。作为一线的体育教师, 要想把自己的队伍带好, 不断学习新的教育理念是 必不可少的, 提高体育教师的综合素质, 特别是教师自身的足球能力, 必须要学习, 一是外 出学习培训, 外出学习培训由于时间和资金因素, 只能涉及到极少部分的教师, 因此通过外 出学习新的战术理念对于所有的一线体育教师来说实现的困难程度非常大, 难以实现。二是 在校学习, 通过传帮带的手段, 外出学习的教师回校后对在校的体育教师进行培训, 向他们 传授新的教育理念, 三是通过互联网可以查阅最先进的战术理念及知识, 还可以通过观看视 频来加深对战术的理解。教师自身的综合素质提高使得在雾䨪天气常态化的情况下, 可以通 过多媒体技术、讲授最先进的足球理念等多种手段与方式向学生传递校园足球文化的相关知 识。因此不断加强体育教师的综合素质对校园足球文化的建设有着至关重要的作用。

\section{1 .2 加强校园足球文化的氛围建设。}

加强校园足球文化的宣传, 让足球文化遍布整个校园，使学生能时刻的享受到校园足球 文化的熏陶。譬如通过各年级各班举办关于足球方面黑板板报竞赛, 让学生利用网上资源或 查阅书籍或者访问体育教师, 主要是初步了解足球运动的起源、足球运动的历史, 足球比赛 的规则、国内外足球运动的发展情况, 著名球队、球星以及学校开展足球运动的情况, 激发 学生对足球的兴趣。加强校园足球文化的氛围建设就要加强足球课程建设。目前的大部分中 小校没有专门的开设足球课程, 只有课余足球训练, 学生接触到足球的时间有限, 接触足球 的学生人数也有限。一周开设一节足球课, 对校园足球文化建设具有促进作用, 学生可以在 课堂上系统地了解和学习足球知识和技巧。开设足球课以后, 学校要安排专业的足球人员进 行教学, 结合课上教学和课外比赛的教学模式, 巩固学生对足球知识及技巧的学习。

\subsection{3完善足球梯队建设}

\subsubsection{1形成足球兴趣小组}

根据学生需要、学生年龄特点成立不同年龄段足球兴趣小组, 实行分层教学。低年级段, 在游戏中学习足球, 培养学生热爱足球的热情。加强学生柔韧性、协调性、灵活性的训练。 高年级年龄段的学生, 学习基本技术和基本技能, 提高学生的能力。

\subsubsection{2严格要求, 规范训练}

学校足球训练应有年度计划, 工作安排, 训练目标。教练员要有明确分工, 任务要求。 管理人员按训练计划进行检查, 使整个活动有计划、有目标、有安排, 抓落实上下功夫。 


\subsubsection{3交流学习，积极参加各类比赛}

足球运动要注重比赛交流。在学校开展校级足球联赛, 与兄弟学校进行交流。有条件的 学校还可以参加俱乐部、市级、省级, 全国性足球邀请赛等等一系列活动。通过比赛交流, 学习他人的经验, 锻炼学生, 提高教学, 促进工作, 总结经验。

\subsection{4形成有效的校园足球联赛机制}

校园足球的发展, 需要配套的联赛体制, 比赛可以激发孩子的激情、引起全社会对足球运 动的关注, 有助于形成浓厚的足球文化氛围。校园足球通过这几年的发展, 市里每年都举办 了中小学组别的足球联赛, 但是由于种种原因, 参与联赛的学校并不是很多, 比赛也就集中 两三天就结束, 还没达到联赛的要求。同时, 中小学校校内也应该开展校级足球联赛, 让更 多的学生参与到校园足球中来。校园足球联赛可以推动校园足球运动的发展, 提高学生足球 竞技水平, 给学生提供共更多的交流平台, 让学生亲身体会足球比赛乐趣与辛苦。

\section{2 改变校园足球教学形式与内容}

\subsection{1校园足球教学形式的改变}

当今社会, 互联网完全融入人们的生活, 各行各业都在提倡利用 “互联网+” 的形式。因此, 在雾霳常态化下如何更好的运用互联网在校园足球教学尤为重要。

足球训练特别是技术训练是非常枯燥的, 特别是对中小学生来说, 不断重复的动作技术训 练会让学生训练的积极性大大下降。在雾霧天气的情况下校园足球的教学, 教师可以利用互 联网让学生通过观看相关视频从而激发学生的训练积极性。同样校园足球的战术训练也可以 利用互联网来进行, 在这个发达的互联网时代, 信息传播速度越来越快, 先进的信息和知识都 可以在互联网上找到, 并加以借鉴。在雾䨪天气时, 教师可以从互联网上下载有关本节课练 习内容的动作图片和视频, 先让学生观看视频动作, 建立完整动作的初步印象, 同时激发学 生练习的热情, 然后教师结合下载的图片进行分解动作讲解, 使学生建立更加直观的印象, 再让学生结合动作图片进行练习。通过观看动作视频和图片, 一方面能够弥补教师的短角, 另一方面提高学生学习兴趣, 大大的提高了教学的效果。因此, 在雾䨪天气的情况下利用互 “互联网+”的教学手段是一种有效的教学形式。

\subsection{2 校园足球教学内容的改变}

\subsubsection{1校园足球文化}

校园足球活动就是以增强学生体质, 培养青少年拼搏进取、团结协作的体育精神为宗旨, 通过广泛开展校园足球活动, 在青少年学生中普及足球知识和技能, 形成校园足球文化。在 在雾皬常态化下, 校园足球的教学可以以建设和宣传校园足球文化作为主要内容之一, 利用 “互联网+” 的形式向学生宣传足球文化, 让学生在思想和心理受到足球文化的熏陶, 形成良 好的校园足球文化氛围, 激发学生对足球运动的热爱。

\subsubsection{2加强身体素质训练}

足球运动中运动员的跑动距离长, 强度大, 而且其中伴随着大量的对抗性动作, 要求身体 素质很高。足球运动中的基本身体素质就是指速度力量素质, 这也将是校园足球活动训练的 重点。在雾䨪天气情况下, 教师可以利用楼道, 门厅, 走廊, 教室等室内场所进行专项身体 素质训练。运用上下楼梯, 开展跳台阶、攀登等练习, 发展学生的下肢力量。运用走廊进行平 板支撑, 发展学生上肢力量和整体力量。利用门厅进行负重跑动、蛙跳、负重深蹲等增加下 肢力量和整体力量的方法。在教室, 教师运用摆放整齐的桌椅, 开展钻, 爬, 平衡等身体练 习，发展学生的身体控制能力以及灵敏素质。

\subsubsection{3开发足球校本课程}

足球校本课程的开发, 能够促进学生的全面、和谐的发展, 更好的彰显学校的办学特色。 
在雾䨪常态化下, 体育教师应根据学校的具体情况, 遵循快乐性原则, 激励性原则, 科学性 原则, 层次性原则开发出适合学校发展, 促进学生全面和谐的校本足球课程。足球校本课程 的内容不仅仅包含足球基础知识、常见的身体素质锻炼、足球技术、足球战术、足球规则等, 足球文化、健康知识、足球礼仪以及常见伤病的预防都可以纳入到足球校本课程中来。譬如 在雾䨱天气情况下, 教师可以在教室组织学生制作简易足球、绘制足球场地、描绘足球活动 场景和活动心情，制作足球方面的手抄报等等。

\section{3 加强学校体育场馆建设}

在近年雾䨪频发的时期, 当前大部分学校的体育基础设施之严重不足, 真正要实现教育的 现代化, 还需要走很长的一段路程。虽然国家的大方针是要求五位一体, 并且下大力气在解 决环境污染的问题, 但这不是一朝一夕就能够改善的。在此期间, 学校要在努力配合国家治 理污染的同时, 加强自己的校园环境和体育场馆建设, 改善体育教学环境, 这才是应对雾䨪 保障校园足球开展的有效途径。雾霧污染已非常严重, 通过改善体育场馆来满足校园足球开 展的需求, 仅仅是小部分学校能够办到, 并不能真正解决整个教学环境, 对整个校园足球的 推广来讲更是杯水车薪。因此, 学校在改善场馆的同时要有环保、绿色的理念, 要有建设生 态校园的远大目标, 把走出课堂、走进自然、走进阳关的阳关体育理念贯穿其中。校园足球 大部分情况是在室外进行, 受外部环境影响非常大, 因此, 在场馆建设之初就要做出合理安 排, 远离空气、噪音等污染源, 把污染尽可能从源头斩断, 尽量的多种植一些吸尘植被和能 够净化环境的树木。花花草草, 郁郁憼葱, 给学生制造一个天然的绿色活动屏障, 为学生创造 一个良好的学习, 运动环境。

\section{3. 结束语}

雾霳天气使得中小学校园足球训练大都转入了教室, 使得教学内容、运动强度、运动密度、 运动时间都得不到保障, 训练的效果明显下降, 污染的治理又是一个长期的系统工程, 非一 日之功所能见效, 因此面对雾霾天气, 教师要根据具体情况, 改变教学思路, 加强校园足球 文化建设, 积极开发适合本校的足球校本课程, 充分利用互联网及多媒体技术来应用于校园 足球训练及教学中。总之, 在雾霧常态化的今天, 如何更加科学合理地开展校园足球, 还有 待于各位体育教师在今后的体育教学实践中不断地摸索与实践。

\section{References}

[1] Fan Guoqiang, Sun Qibin, Qian Shuaiwei.Influence of Haze Fog Weather on Physical Training and the Countermeasures[J].China Academic Journal Electronic Publishing House 2015.1

[2] ZhouXingfen, The Research of the Strategy about School Sports under the Haze Weather Normalization,[J]Contemporary Sports Technology,2014.4

[3] WangJinhui .Haze New Threat to School Sports[J], Journal of DaQing Normal University,2014.5

[4] Li ChunluHaze .Weather Sports Damage Analysis of the Respiratory System[J].Bulletin of Science And Technology,2014.1

[5] Lin Qi.Construction of Junior High School Football Teaching System under the Background of Youth Campus Football[J]. Xinkecheng Xuexi.2014.9

[6] Li Weidong, Zhang Ting an, Lu Yu , On the Situation of Junior School Soccer in China. [J].Journal of Shang Hai University of Sport.2011.9 